\title{
Investigating polymorphisms by bioinformatics is a potential cost-effective method to screen for germline mutations in Chinese familial adenomatous polyposis patients
}

\author{
JUN YANG ${ }^{1}$, WEI QING LIU ${ }^{2}$, WEN LIANG LI ${ }^{1}$, CHENG CHEN $^{1}$, ZHU ZHU $^{1}$, \\ MIN HONG ${ }^{2}$, ZHI QIANG WANG ${ }^{1}$ and JIAN DONG ${ }^{2,3}$
}

Departments of ${ }^{1}$ Oncology and ${ }^{2}$ Internal Medicine-Oncology, First Affiliated Hospital of Kunming Medical University, Kunming, Yunnan 650032; ${ }^{3}$ Department of Internal Medicine-Oncology,

Third Affiliated Hospital of Kunming Medical University, Kunming, Yunnan 650106, P.R. China

Received January 22, 2015; Accepted April 12, 2016

DOI: $10.3892 / \mathrm{ol} .2016 .4646$

\begin{abstract}
The aim of this study was to investigate germline mutations of the APC, MUTYH and AXIN2 genes in Chinese patients with familial adenomatous polyposis (FAP), and further assess the value of bioinformatics in screening the pathogenic changes predisposing to FAP. APC genes from 11 unrelated FAP patients in Yunnan province in China were firstly examined by exon-specific DNA sequencing. For samples without already known pathogenic changes predisposing to FAP in the APC gene, whole-gene sequencing of MUTYH and AXIN2 was performed. Mutational analysis of each gene was performed by bioinformatics. Eleven different types of APC polymorphisms were observed in the cohort of families analyzed. Of these polymorphisms, four were missense substitutions (V1822D, V1173G, P1760H and K2057), one was a nonsense substitution (S1196X), and six were silent substitutions (Y486Y, T449T, T1493T, G1678G, S1756S and P1960P). One missense mutation $(\mathrm{Q} 335 \mathrm{H})$ and two intronic substitutions $(\mathrm{c} .264+11 \mathrm{G}>\mathrm{A}$ and c. $420+35 \mathrm{~A}>\mathrm{G}$ ) were detected in the MUTYH gene, and four synonymous mutations (I144I, P455P, P462P and L688L) and three intonic mutations (c.1060-77G $>$ T, c.1060-287A>G and c.1060-282 A>G) of the AXIN2 gene were observed. In addition to the already reported pathogenic mutations, by using function assessment tools and databases, the synonymous substitutions observed in the APC gene of our samples were predicted to affect splicing regulation in the translation of mRNA, while the missense mutations observed in the APC gene and MUTYH gene were predicted to be disease-related polymorphisms; however, no functional effect of the mutations
\end{abstract}

Correspondence to: Dr Jian Dong, Department of Internal Medicine-Oncology, Third Affiliated Hospital of Kunming Medical University, 519 Kunzhou Road, Kunming, Yunnan 650106, P.R. China

E-mail: youngjean1982@aliyun.com

Key words: familial adenomatous polyposis, pathogenic changes, mutation analysis, functional prediction, bioinformatic tools was observed in the AXIN2 gene. Comprehensive screening for germline mutations in APC, MUTYH and AXIN2 genes followed by prediction of pathogenicity using bioinformatic tools contributes to a cost-effective way of screening germline mutations in Chinese familial adenomatous polyposis patients.

\section{Introduction}

Familial adenomatous polyposis (FAP) is an autosomal dominantly inherited disease (1), which is characterized by the development of hundreds to thousands of adenomatous polyps in the colon and rectum (2) during the second and third decades of life. If these polyps are not removed, most FAP patients progress to colorectal cancer (CRC) (3). It is well known that FAP is linked to germline mutations of the adenomatous polyposis coli (APC) gene (5q21-q22; OMIM \#175100) $(4,5)$, which consists of 15 coding exons and an 8538 bp open reading frame. In 1991, Groden et al described FAP as an autosomal-dominant disorder caused by germline mutations of APC (5). The examination of APC germline mutations in FAP families is currently considered an efficient tool for predictive testing of subjects at risk. To date, over 1500 different pathogenic APC mutations have been reported in the Leiden Open Variation Database (http://www.lovd.nl/2.0/).

At present, a number studies on the genetic screening of FAP in China (6-9) and other countries have been reported; however, the detection rate and the associated mutations vary markedly (10-15). A number of patients with FAP have no APC mutation. Among the known genes, evidence from previous studies suggests that MUTYH mutations observed in FAP patients may explain up to $25 \%$ of 'APC mutation-negative' FAP (16-18). In addition, AXIN2, which is involved in the Wnt signaling pathway, has also been selected as a candidate gene for FAP (19).

A large number of factors which might predispose individuals to FAP have been reported; however, further analysis of the pathogenesis of disease-associated variants still presents a significant challenge and huge cost. With the rapid development of science and technology, tools and databases for the prediction of pathogenicity have been promoted, and the tests 
to verify the predicted results are inspiring. For example, certain synonymous mutations, which were sometimes considered as silent mutations, are now widely acknowledged to be capable of causing changes in protein expression, conformation and function.

In our study, in order to investigate germline mutations in Chinese patients with FAP, a total of 11 FAP patients were selected for exon-specific DNA sequencing of the APC gene to determine the micromutation type. For samples without known pathogenic changes predisposing to FAP in the APC gene, whole-gene sequencing of the MUTYH gene and AXIN2 gene was further performed. Due to the high cost and the long time required for the analysis of huge amounts of data, the pathogenicity of amino acid substitution identified in our study was tested and predicted by computational methods.

\section{Patients and methods}

Ethics. This study was approved by and carried out in accordance with the Research Ethics Board of the First Affiliated Hospital of Kunming Medical University (Kunming, China). All subjects provided their written informed consent to participate in this study. The ethics committees approved the consent procedure.

Subject recruitment. From 2005 to 2013, 11 FAP patients were recruited from the Department of Oncology, at the First Affiliated Hospital of Kunming Medical University. All patients were referred to this study initially based on clinically suspicious colonoscopic findings, and the diagnosis of FAP was subsequently confirmed by surgery or endoscopic mucosal resection and through a suggestive family history of FAP.

Genomic DNA purification. Peripheral venous blood (10 ml) was drawn from FAP patients and genomic DNA was purified following the instructions of the DNA extraction kit (QIAamp DNA blood mini kit, Qiagen, Valencia, CA, USA). The extracted DNA was quantified by a Pearl nanophotometer (Implen, Munich, Germany).

Exon-specific DNA sequencing of APC. All FAP patients underwent exon-specific DNA sequencing of APC. The 1-14 exons of the promoter region and the 21 segments of the 15 th exon in the APC gene were amplified separately by polymerase chain reaction (PCR). The primer pairs were designed as previously described (20). All samples were amplified in $20 \mu \mathrm{l}$ reaction mixture containing $50 \mathrm{ng}$ genomic DNA, $10 \mathrm{mM}$ Tris- $\mathrm{HCl}, 50 \mathrm{mM} \mathrm{KCl,} 2.5 \mathrm{mM} \mathrm{MgCl}$, $0.2 \mathrm{mM}$ each $\mathrm{dNTP}$, $200 \mathrm{mM}$ each primer, 5\% DMSO and 0.01 units Ex Taq polymerase (Takara, Tokyo, Japan). The thermal cycling profile was composed of an initial denaturation step at $94^{\circ} \mathrm{C}$ for $5 \mathrm{~min}$, 30 cycles of $30 \mathrm{sec}$ of denaturation at $94^{\circ} \mathrm{C}, 30 \mathrm{sec}$ of annealing at $58^{\circ} \mathrm{C}$, and $45 \mathrm{sec}$ of extension at $72^{\circ} \mathrm{C}$, with a final 10 -min extension step at $72^{\circ} \mathrm{C}$. After observing by agarose gel electrophoresis, PCR products were purified using a MiniBEST Universal DNA extraction kit (Takara). DNA sequencing reactions were performed using a BigDye Terminator v3.1 Cycle sequencing kit (Applied Biosystems, Foster City, CA, USA). Nucleotide sequences of both strands were determined with an ABI Prism 3730 genetic analyzer (Applied Biosystems).
Whole-gene sequencing of MUTYH. For the six patients without direct pathogenic changes predisposing to FAP in the APC gene (i.e., patients for whom samples presented synonymous mutations only), MUTYH mutation screening was carried out. Whole-gene sequencing of the MUTYH gene was performed; the primer pairs used for MUTYH sequencing in this study were designed as previously described (21). All samples were amplified in $20 \mu \mathrm{l}$ reaction mixture. The PCR cycling profile was composed of an initial denaturation step at $95^{\circ} \mathrm{C}$ for $5 \mathrm{~min}, 30$ cycles of $30 \mathrm{sec}$ of denaturation at $95^{\circ} \mathrm{C}$, $1 \mathrm{~min}$ of annealing at $57^{\circ} \mathrm{C}$, and $1.5 \mathrm{~min}$ of extension at $72^{\circ} \mathrm{C}$, with a final 8 -min extension step at $72^{\circ} \mathrm{C}$. After purifying the PCR products, DNA sequencing was applied and analyzed.

AXIN2 mutation screening. The Wnt signaling regulator gene AXIN2 was tested in the same batch of samples following the screening of the MUTYH gene. The coding region of AXIN2 was sequenced for mutations exon by exon using primers and conditions as previously described (19). The PCR products were analyzed by DNA sequencing.

Mutation analysis. The sequencing data of each gene tested were firstly analyzed using Mutation Surveyor by SoftGenetics (http://www.softgenetics.com/). For mutations of the APC gene, the UMD APC mutations database (http://www.umd.be/APC/), APC-Database (http://www.LOVD.nl/APC), Zhejiang University-Adinovo Center APC Database $(22,23)$ (http://www. genomed.org/lovd2/home.php?select_db=APC) and the APC Mutation Database (http://fap.taenzer.me) were applied to screen for the presence of novel and already-known variants. For the mutation screening of the MUTYH gene, the MUTYH Mutation Database (http://www.LOVD.nl/MUTYH) was used. For mutations of the AXIN2 gene, Zhejiang University Center for Genetic and Genomic Medicine (ZJU-CGGM) $(22,23)$ (http://www.genomed.org/lovd2/home.php?select_db=AXIN2) was consulted. In addition to the above-mentioned tools and websites for the mutation screening of each gene, the Human Gene Mutation Database (http://www.hgmd.org/), International HapMap Project (www.hapmap.org/), Nucleotide Variation and Mutation Database (http://www.mutationdiscovery. com/md/MD.com/home_page.jsp), dbSNP database (24) (http://www.ncbi.nlm.nih.gov/SNP/), 1000 Genomes (http://www.1000genomes.org/), and Ensembl (25) (www. ensembl.org/) were also used.

In silico analysis. Mutations identified from each gene identified in our study were analyzed using an extensive set of assessment tools and databases. For the already known amino acid substitutions, their corresponding SNP IDs were confirmed. For each mutation, a series of tests was executed to determine whether the mutation had a functional impact with respect to functional categories including protein coding, splicing regulation, transcriptional regulation and post-translation. For the prediction of deleterious missense mutations, PolyPhen-2 (26), SIFT (27) and SNPs\&GO (28-30) were used. For the illustration of conserved amino acids, Pfam (http://pfam.sanger.ac.uk/) (31), Clustal W2 (http://www.ebi. ac.uk/Tools/msa/clustalw2/) (32) and Jalview (http://www. jalview.org/) (33) were used. The functional consequences of synonymous and intronic mutations identified in our study were 
Table I. Characteristics of familial adenomatous polyposis patients $(n=11)$ treated at our institution between 2005 and 2013.

\begin{tabular}{lcccc}
\hline Age & Gender & Number of adenomas & Treatment & Diagnosis of CRC \\
\hline 29 & M & $>1,000$ & Surgery & Yes \\
22 & M & $>1,000$ & Surgery & Yes \\
35 & M & $>1,000$ & Surgery & Yes \\
36 & M & $500-1,000$ & Surgery & Yes \\
26 & M & $>1,000$ & Surgery & Yes \\
25 & M & $>1,000$ & Surgery & Yes \\
32 & F & $>1,000$ & Surgery & Yes \\
29 & F & $>1,000$ & Surgery & No \\
29 & F & $100-200$ & EMR & Yes \\
18 & F & $>1,000$ & Surgery & Yes \\
27 & F & $>1,000$ & Surgery &
\end{tabular}

${ }^{a}$ The surgical strategy for familial adenomatous polyposis patients is ileal pouch-anal anastomosis. M, male; F, female; CRC, colorectal cancer; EMR, endoscopic mucosal resection.

Table II. Variants identified in each patient.

\begin{tabular}{|c|c|c|c|c|}
\hline Gene & $\begin{array}{c}\text { Exon or } \\
\text { intron }\end{array}$ & Variant & Function class & Case no. \\
\hline \multirow[t]{11}{*}{$\mathrm{APC}$} & 11 & c.1458T>C (P. Y486Y) & Synonymous substitution & II, III and IV \\
\hline & 11 & c.1347G >C (p. T449T) & Synonymous substitution & III, IV, IX and XI \\
\hline & 15 & c. $3518 \mathrm{~T}>\mathrm{G}(\mathrm{p} .1173 \mathrm{~V}>\mathrm{G})$ & Missense substitution & II, IV, V, VIII, IX and XI \\
\hline & 15 & c. $3587 \mathrm{C}>\mathrm{A}(\mathrm{p} . \mathrm{S} 1196 \mathrm{X})$ & Nonsense substitution & IV \\
\hline & 15 & c.4425G >A (p. T1493T) & Synonymous substitution & III, VIII and IX \\
\hline & 15 & c.5034 G>A (p. G1678G) & Synonymous substitution & III and IX \\
\hline & 15 & c.5268T>G (p. S1756S) & Synonymous substitution & II, III, IV and VIII \\
\hline & 15 & c. $5279 \mathrm{C}>\mathrm{A}(\mathrm{p} .1760 \mathrm{P}>\mathrm{H})$ & Missense substitution & II, III and IV \\
\hline & 15 & c. $5880 \mathrm{G}>\mathrm{A}(\mathrm{p} . \mathrm{P} 1960 \mathrm{P})$ & Synonymous substitution & IV, VIII, IX and XI \\
\hline & 15 & c.5465T>A (p. V1822D) & Missense substitution & I, IV, VI, VII and X \\
\hline & 15 & c.6170A>G (p. K2057R) & Missense substitution & II, IX and XI \\
\hline \multirow[t]{4}{*}{ MUTYH } & 11 & c. $1005 \mathrm{C}>\mathrm{G}(\mathrm{p} . \mathrm{Q} 335 \mathrm{H})$ & Missense substitution & II, III, V, VIII, IX and XI \\
\hline & IVS5 & c. $264+11 G>A$ & Intronic mutation & II, III, V, VIII, IX and XI \\
\hline & IVS5 & c. $420+35 \mathrm{~A}>\mathrm{G}$ & Intronic mutation & II, III, V, VIII, IX and XI \\
\hline & & & & II, III, V, VIII, IX and XI \\
\hline \multirow[t]{7}{*}{ AXIN2 } & 2 & c.432T>C (p. I144I) & Synonymous substitution & II, III, V, VIII, IX and XI \\
\hline & 6 & c. $1365 \mathrm{~A}>\mathrm{G}$ (p. P455P) & Synonymous substitution & II, III, V, VIII, IX and XI \\
\hline & 6 & c.1386C>T9 (p. P462P) & Synonymous substitution & II, III, V, VIII, IX and XI \\
\hline & 8 & c. $2062 \mathrm{C}>\mathrm{T}$ (p. L688L) & Synonymous substitution & II, III, V, VIII, IX and XI \\
\hline & IVS3 & c. $1060-287 \mathrm{~A}>\mathrm{G}$ & Intronic mutation & II, III, V, VIII, IX and XI \\
\hline & IVS3 & c. $1060-282 \mathrm{~A}>\mathrm{G}$ & Intronic mutation & II, III, V, VIII, IX and XI \\
\hline & IVS3 & c. $1060-77 \mathrm{G}>\mathrm{T}$ & Intronic mutation & II, III, V, VIII, IX and XI \\
\hline
\end{tabular}

predicted by the splicing prediction programs ESEfinder (34), ESRSearch (35), PESX (36) and RESCUE_ESE (37).

\section{Results}

Patient characteristics. Eleven Chinese FAP patients with a clinical diagnosis of classical were included in this study. The group comprised 6 males and 5 females (mean age, 28 years; range, 18-36 years). The age and gender distribution between the two groups were not significantly different. The patient characteristics are summarized in Table I.

Micromutations of each gene. After DNA sequencing of the APC, MUTYH and AXIN2 genes, the micromutations of each 
Table III. Computational predictions of deleterious missense mutations.

\begin{tabular}{|c|c|c|c|c|c|c|c|}
\hline Gene & Exon & Variant & dbSNP ID & Function class & PolyPhen- $2^{\mathrm{a}}$ & SIFT $^{b}$ & $\mathrm{SNPs}_{\mathrm{SGO}}{ }^{\mathrm{c}}$ \\
\hline APC & 15 & c. $3518 \mathrm{~T}>\mathrm{G}(\mathrm{p} .1173 \mathrm{~V}>\mathrm{G})$ & Novel & Missense mutation & Benign (0.003) & Tolerated (0.540) & Disease \\
\hline APC & 15 & c. $5279 \mathrm{C}>\mathrm{A}(\mathrm{p} .1760 \mathrm{P}>\mathrm{H})$ & Novel & Missense mutation & Benign (0.039) & Tolerated (0.100) & Disease \\
\hline APC & 15 & c.5465T>A (p. V1822D) & rs459552 & Missense mutation & Benign (0.000) & $\begin{array}{l}\text { Affected protein } \\
\text { function }(0.000)\end{array}$ & Disease \\
\hline $\mathrm{APC}$ & 15 & c.6170A>G (p. K2057R) & Novel & Missense mutation & Benign (0.411) & Tolerated (0.470) & Disease \\
\hline MUTYH & 11 & c.1005 C>G (p. Q335H) & rs3219489 & Missense mutation & Benign (0.124) & Tolerated (0.140) & Disease \\
\hline
\end{tabular}

${ }^{\mathrm{a}} \mathrm{A}$ figure $>0.50$ is predicted to be damaging. ${ }^{\mathrm{b}} \mathrm{Amino}$ acids with probabilities $<0.05$ are predicted to be deleterious. ${ }^{\mathrm{c}}$ Disease-related polymorphism.

15 aa repeat

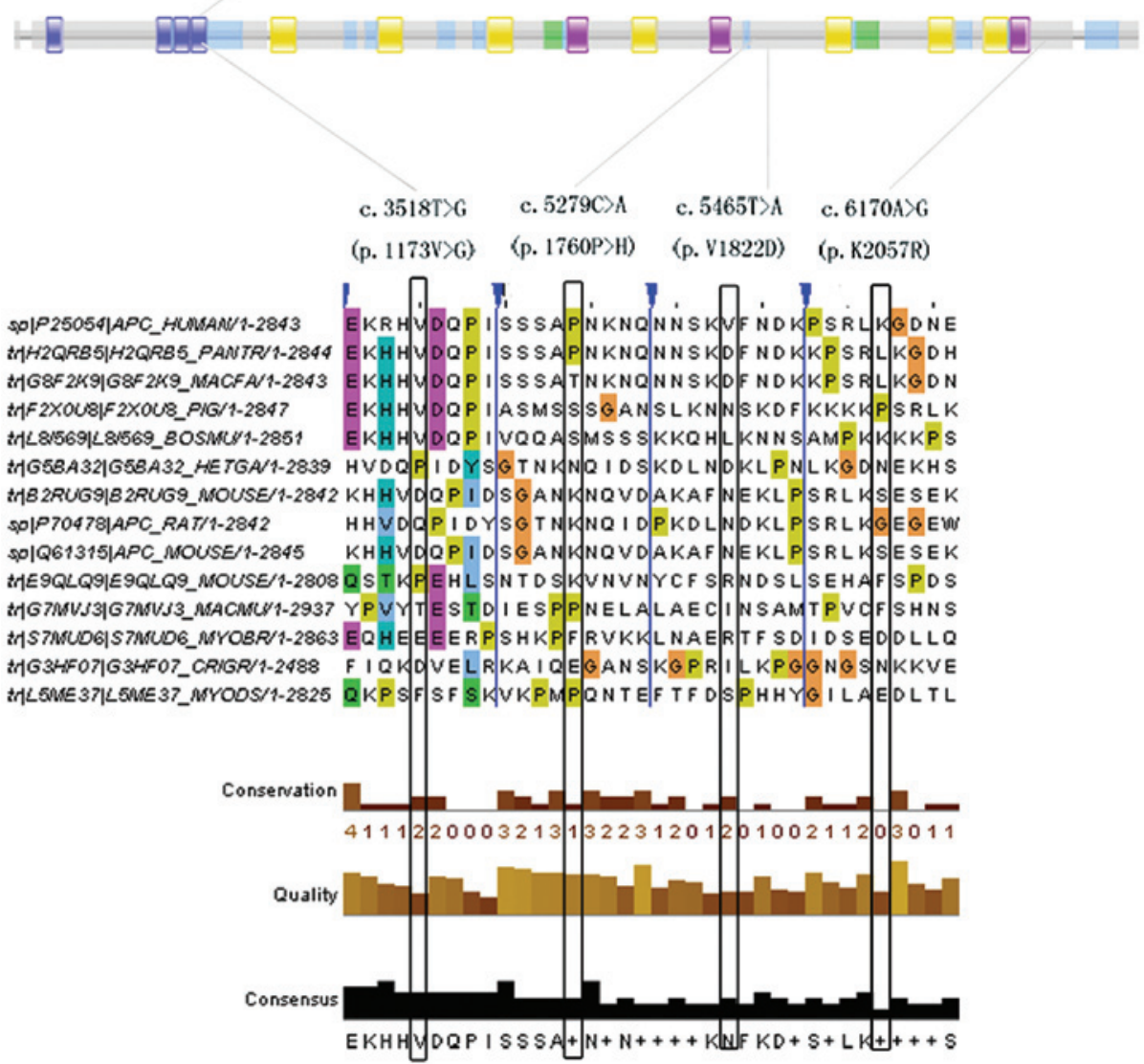

Figure 1. Distribution of mutations identified in the APC gene in individuals with familial adenomatous polyposis. Top, Pfam domains of APC protein domains. Bottom, multiple sequence alignment of the amino acids encoded by exon 11 and 15 of APC gene.

gene were analyzed by Mutation Surveyor, and the mutations are summarized in Table II. Eleven different types of APC polymorphism were observed in the cohort of the families analyzed, of which four were missense substitutions (V1822D, V1173G, P1760H and K2057), six were silent substitutions (Y486Y, T449T, T1493T, G1678G, S1756S and P1960P) and one was a nonsense substitution (S1196X). The nonsense substitution (S1196X) in the APC gene was an already-known pathogenic mutation, which resulted in a stop codon at codon 1196 and generated a premature truncated protein (38). In addition, one missense mutation $(\mathrm{Q} 335 \mathrm{H})$ and two intronic substitutions (c. $264+11 \mathrm{G}>\mathrm{A}$ and c. $420+35 \mathrm{~A}>\mathrm{G}$ ) were identified in the MUTYH gene, and four synonymous mutations (I144I, $\mathrm{P} 455 \mathrm{P}, \mathrm{P} 462 \mathrm{P}$ and L688L) and three intonic mutations (c.1060-77G $>$ T, c.1060-287A $>$ G and c.1060-282A $>$ G) were identified in the AXIN2 gene.

Computational prediction of missense substitutions. Among the APC missense substitutions identified in our study, the functional assessment of V1822D indicated that it is a deleterious mutation, and the bioinformatic result was consistent with that of previous studies, which considered it as a high-risk polymorphism associated with CRC (39-41). Computational prediction suggested that the missense substitutions in the 


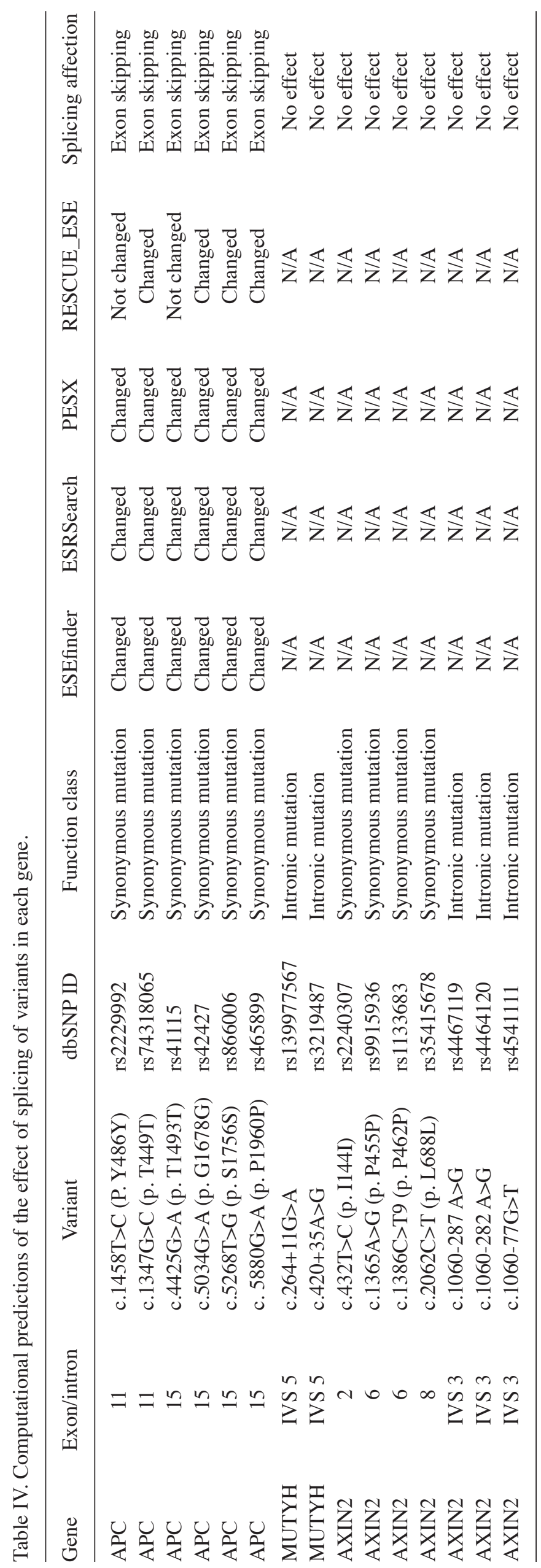

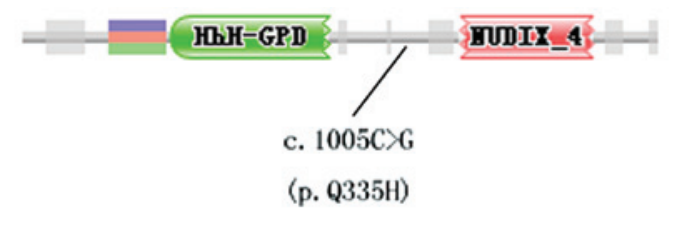

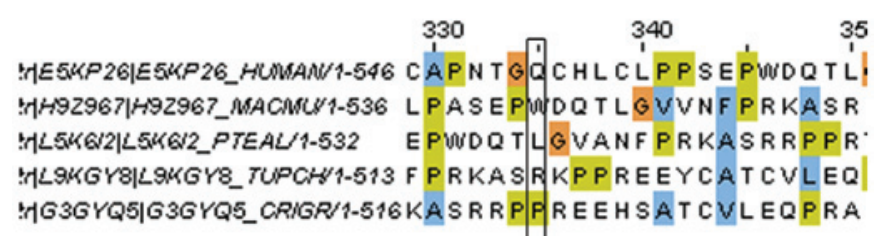

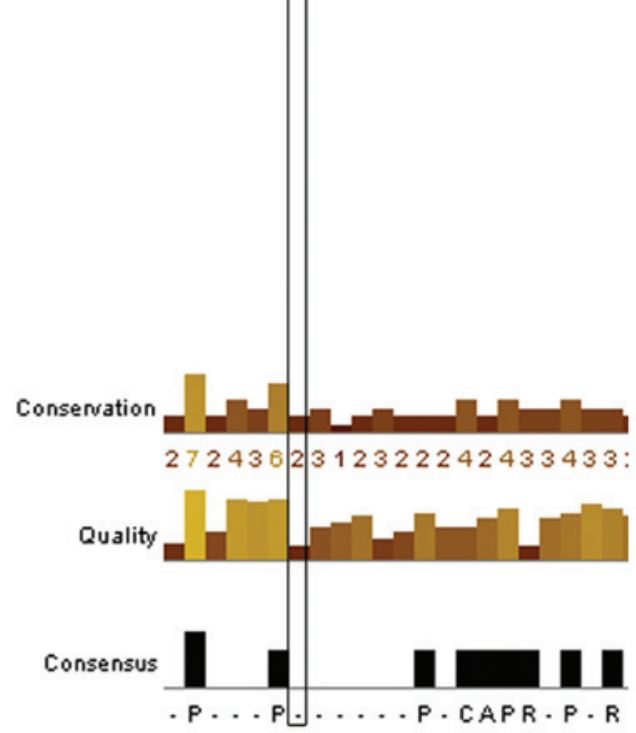

Figure 2. Distribution of mutations identified in the MUTYH gene in individuals with familial adenomatous polyposis. Top, Pfam domains of MUTYH protein domains. Bottom, multiple sequence alignment of the amino acids encoded by exon 15 of MUTYH gene.

APC and MUTYH gene might be disease-associated variants (Table III, Figs. 1 and 2). It is of note that the novel APC missense substitution (V1173G), which mapped to the fourth 15aa repeat region of the APC protein, an essential region involved in binding with $\beta$-catenin, might be associated with the early onset of FAP (42).

Splicing regulation of synonymous and intronic substitutions. Synonymous and intronic substitutions of each gene were further analyzed (Table IV). In silico analysis results indicated that the six already known synonymous substitutions (Y486Y, T449T, T1493T, G1678G, S1756S and P1960P) might affect splicing regulation by creating or removing exonic splicing enhancers or exonic splicing silencers; however, in previous studies of these synonymous substitutions, they were considered to be 'silent' substitutions $(43,44)$. No effect was detected in the synonymous or intonic substitutions of the AXIN2 gene.

\section{Discussion}

Due to the poor prognosis of FAP and its genetic diversity, clinicians and researchers study FAP from various angles, each having their own agenda. Recent advances in our understanding of FAP suggest that the genetics of each patient might help to clarify diagnosis, lead to early cancer surveillance 
options, and guide surgical and chemopreventive management for FAP patients. However, the genetics of FAP vary markedly among different countries (9-15). FAP in China has its own characteristics $(6-9,45)$, which may be explained by the abundant genetic resources in 56 nationalities as well as religious differences. The present study is a comprehensive mutational analysis of FAP in Yunnan province in southwest China. Indigenous people in this area live in a relatively closed environment; thus, 11 unrelated FAP patients from this area were analyzed to screen for pathogenic changes.

It is well known that FAP is linked to germline mutations in the APC gene (4,5). In our study, mutational analysis of the APC gene was firstly conducted, and one known missense mutation (V1822D) and one previously identified nonsense mutation (S1196X) were observed. The missense mutation (V1822D) was identified in five FAP patients in our research indices, and it was established that the missense substitution is a high-risk polymorphism associated with CRC (39-41). In addition, a nonsense mutation (S1196X) was identified in one of the five patients with the missense mutation V1822D. The nonsense mutation S1196X was reported to be a pathogenic change predisposing to FAP (38), which results in a stop codon at codon 1196 and generates a premature truncated protein. Additionally, certain synonymous mutations of the APC gene were identified in the different FAP patients; six different synonymous mutations (Y486Y, T449T, T1493T, G1678G, S1756S and P1960P) were identified in all samples, which were considered as silent mutations in the past. By referring to previous studies and databases $(22,38-41)$, we were able to identify pathogenic mutations in 5 of the 11 index cases in our series, and the detection rate was $54.5 \%$.

The detection rate of APC mutations in FAP patients varies significantly, ranging from 39 to $90 \%$ (10-15). The mutation negativity of the APC gene may suggest either that APC has alterations that escape detection by routine techniques, or alternatively, that other (known or unknown) genes are involved in FAP predisposition (18). Among the known genes, the identification of germline mutations in MUTYH and AXIN2 involved in FAP predisposition have been reported (16-19). Therefore, in the remaining six patients without already known pathogenic changes involved in FAP (patients presenting APC synonymous mutations), whole-gene sequencing of the MUTYH gene and AXIN2 gene was further performed. The results indicated that two intronic substitutions (c. $264+11 \mathrm{G}>\mathrm{A}$ and c. $420+35 \mathrm{~A}>\mathrm{G}$ ) and one missense mutation $(\mathrm{Q} 335 \mathrm{H})$ were present in the MUTYH gene, and four synonymous mutations (I144I, P455P, P462P and L688 L) and three intonic mutations (c.1060-77G >T, c.1060-287A>G and c.1060-282 A>G) were present in the AXIN2 gene.

Like the synonymous mutations observed in APC, these findings in MUTYH and AXIN2 are still of little use for the genetic diagnosis of FAP. However, the repeated synonymous and intronic mutations in the different patients are of note. Traditionally, synonymous substitutions and certain intronic mutations were assumed not to cause significant changes in the function of coded proteins. However, this idea changed with the observation that silent mutations may cause human diseases $(46,47)$, and numerous cancer-associated synonymous substitutions have been reported (48). Accumulated evidence suggests that certain synonymous and intronic mutations may result in altered splicing, which may directly cause disease, modify the severity of the disease phenotype, or be linked with disease susceptibility (49-52). Approximately $15 \%$ of disease-causing point mutations affect pre-mRNA splicing (53), resulting in the activation of cryptic sites, creation of a pseudo-exon within an intron, intron retention, or exon skipping, the latter being the most likely of these events.

With the rapid development of science and technology, numerous tools and databases for the prediction of pathogenicity have been promoted. Using function assessment tools and databases, we further assessed the polymorphisms in each gene, and the results indicated that the synonymous substitutions in the APC gene might be disease-causing point mutations by affecting pre-mRNA splicing and resulting in the pathogenicity of FAP, while the mutations identified in the MUTYH gene and AXIN2 gene demonstrated no impact on predisposing to FAP. Computational prediction suggested that the missense substitutions in the APC gene and MUTYH gene might also be disease-associated variants. It is also worth noting that one of the novel missense substitutions (V1173G) was identified in APC, which was also predicted to be associated with the early onset of FAP.

In our study, following mutation analysis of each gene with conventional methods, we were able to determine the genetic pathogenicity of five FAP patients, with the remaining six patients having no known pathogenic changes involved in FAP. Using function assessment tools and databases, the synonymous mutations of the APC gene were predicted to affect splicing by creating or removing exonic splicing enhancers or exonic splicing silencers, which might result in a pseudo-exon within an intron, intron retention, or exon skipping. Computational prediction of synonymous substitutions suggested that certain synonymous mutations of the APC gene may have a functional impact on the splicing regulation of APC at the mRNA level. Moreover, the missense substitutions in APC and MUTYH were also predicted to be disease-associated variants. These cancer-associated substitutions might explain the pathogenicity of the other six FAP patients in our study, who were previously presenting undetectable pathogenic changes.

In conclusion, based on our study, we consider that it is more beneficial to explore the potential function of the various polymorphisms than to identify rare variants predisposing to FAP. The functional prediction of the mutations is a cost-effective way to identify candidate disease variants in developing countries (54). Further research is required from ex vivo splicing assay and ESE-dependent splicing assay with regard to the synonymous mutations (51). Due to the high cost and the time-consuming process of screening the genetic pathogenicity of FAP, the detection of point mutations by DNA analysis followed by prediction of the pathogenicity may be a useful new strategy to provide proper diagnosis or genetic counseling to patients and their families. This is likely to contribute to better genetic counseling and simplify the mutation screening strategy.

\section{Acknowledgements}

This study was supported by the National Natural Science Foundation of China (no. 81160245) and the Science and 
Technology Planning Project of Yunnan Province, China (no. 2011FB160).

\section{References}

1. Gardner EJ, Burt RW and Freston JW: Gastrointestinal polyposis: syndromes and genetic mechanisms. West J Med 132: 488-499, 1980.

2. Bianchi LK, Buerke CA, Bennett AE, Lopez R, Hasson H and Church JM: Fundic gland polyp dysplasia is common in familial adenomatous polyposis. Clin Gastroenterol Heptatol 6: 180-185, 2008.

3. Nugent KP and Philips RK: Rectal cancer risk in older patients with adenomatous polyposis and ileorectal anastomosis: a cause for concern. Br J Surg 79: 1204-1206, 1992.

4. Kinzler KW, Nilbert MC, Vogelstein B, Bryan TM, Levy DB Smith KJ, Preisinger AC, Hamilton SR, Hedge P and Markham A: Identification of a gene located at chromosome $5 \mathrm{q} 21$ that is mutated in colorectal cancers. Science 251 1366-1370, 1991.

5. Groden J, Thliveris A, Samowitz W, Carlson M, Gelbert L, Albertsen H, Joslyn G, Stevens J, Spirio L and Robertson M: Identification and characterization of the familial adenomatous polyposis coli gene. Cell 66: 589-600, 1991.

6. Liu XR, Shan XN, Friedl W, Uhlhaas S, Li JT, Propping P and Wang YP: Detection of germline mutations in the APC gene with the protein truncation test. Yi Chuan Xue Bao 32: 903-908, 2005 (In Chinese)

7. Gan Y, Zheng S and Cai X: Detection of a gene mutation in familial adenomatous polyposis families by PCR-RFLP method. Zhonghua Yi Xue Za Zhi 74: 352-354, 1994 (In Chinese).

8. Chen S, Zhou J, Zhang X, Zhou X, Zhu M, Zhang Y, Ma G and Li J: Mutation analysis of the APC gene in a Chinese FAP pedigree with unusual phenotype. ISRN Gastroenterol 2011: 909121, 2011

9. Sheng JQ, Cui WJ, Fu L, Jin P, Han Y, Li SJ, Fan RY, Li AQ, Zhang MZ and Li SR: APC gene mutations in Chinese familial adenomatous polyposis patients. World J Gastroenterol 16 : $1522-1526,2010$

10. Vandrovcová J, Štekrová J, Kebrdlová V and Kohoutová M: Molecular analysis of the APC and MYH genes in Czech families affected by FAP or multiple adenomas: 13 novel mutations. Hum Mutat 23: 397, 2004

11. Gómez-Fernández N, Castellví-Bel S, Fernández-Rozadilla C, Balaguer F, Muñoz J, Madrigal I, Milà M, Graña B, Vega A Castells A, et al: Molecular analysis of the APC and MUTYH genes in Galician and Catalonian FAP families: a different spectrum of mutations? BMC Med Genet 10: 57 2009.

12. Rivera B, González S, Sánchez-Tomé E, Blanco I, Mercadillo F, Letón R, Benítez J, Robledo M, Capellá G and Urioste M: Clinical and genetic characterization of classical forms of familial adenomatous polyposis: a Spanish population study. Ann Oncol 22: 903-909, 2011.

13. Fostira F, Thodi G, Sandaltzopoulos R, Fountzilas G and Yannoukakos D: Mutational spectrum of APC and genotype-phenotype correlations in Greek FAP patients. BMC Cancer 10: 389, 2010

14. Torrezan GT, da Silva FC, Santos EM, Krepischi AC, Achatz MI, Aguiar S Jr, Rossi BM and Carraro DM: Mutational spectrum of the APC and MUTYH genes and genotype-phenotype correlations in Brazilian FAP, AFAP and MAP patients. Orphanet J Rare Dis 8: 54, 2013.

15. Kanter-Smoler G, Fritzell K, Rohlin A, Engwall Y, Hallberg B, Bergman A, Meuller J, Grönberg H, Karlsson P, Björk J and Nordling M: Clinical characterization and the mutation spectrum in Swedish adenomatous polyposis families. BMC Med 6: 10, 2008.

16. Al-Tassan N, Chmiel NH, Maynard J, Fleming N, Livingston AL Williams GT, Hodges AK, Davies DR, David SS, Sampson JR and Cheadle JP: Inherited variants of MYH associated with somatic G:C->T:A mutations in colorectal tumors. Nat Genet 30 : 227-232, 2002

17. Sieber OM, Lipton L, Crabtree M, Heinimann K, Fidalgo P, Phillips RK, Bisgaard ML, Orntoft TF, Aaltonen LA Hodgson SV, et al: Multiple colorectal adenomas, classic adenomatous polyposis and germ-line mutations in MYH. N Engl J Med 348: 791-799, 2003.
18. Renkonen ET, Nieminen P, Abdel-Rahman WM, Moisio AL, Järvelä I, Arte S, Järvinen HJ and Peltomäki P: Adenomatous polyposis families that screen APC mutation-negative by conventional methods are genetically heterogeneous. J Clin Oncol 23: 5651-5659, 2005.

19. Lammi L, Arte S, Somer M, Jarvinen H, Lahermo P, Thesleff I, Pirinen $S$ and Nieminen P: Mutations in AXIN2 cause familial tooth agenesis and predispose to colorectal cancer. Am J Hum Genet 74: 1043-1050, 2004

20. Wei SC, Su YN, Tsai-Wu JJ, Wu CH, Huang YL, Sheu JC, Wang CY and Wong JM: Genetic analysis of the APC gene in Taiwanese familial adenomatous polyposis. J Biomed Sci 11: 260-265, 2004.

21. Prior TE and Bridgeman SJ: Identifying mutations for MYH-associated polyposis. Current Protocols in Human Genetics 64 10.13.1-10.13.14, January 1, 2010. DOI: 10.1002/0471142905. hg1013s64.

22. Pan M, Cong P, Wang Y, Lin C, Yuan Y, Dong J, Banerjee S, Zhang T, Chen Y, Zhang T, et al: Novel LOVD databases for hereditary breast cancer and colorectal cancer genes in the Chinese population. Hum Mutat 32: 1335-1340, 2011.

23. Zhang T, Moss A, Cong P, Pan M, Chang B, Zheng L, Fang Q, Zareba W, Robinson J, Lin C, et al; Long QT International Registry Investigators; HVP-China Investigators: LQTS gene LOVD database. Hum Mutat 31: E1801-E1810, 2010.

24. Sherry ST, Ward MH, Kholodov M, Baker J, Phan L, Smigielski EM and Sirotkin K: DbSNP: The NCBI database of genetic variation. Nucleic Acids Res 29: 308-311, 2001.

25. Hubbard TJ, Aken BL, Beal K, Ballester B, Caccamo M, Chen Y, Clarke L, Coates G, Cunningham F, Cutts T, et al: Ensembl 2007. Nucleic Acids Res 35 (Database issue): D610-D617, 2007.

26. Ng PC and Henikoff S: Predicting deleterious amino acid substitutions. Genome Res 11: 863-874, 2001

27. Calabrese R, Capriotti E, Fariselli P, Martelli PL and Casadio R: Functional annotations improve the predictive score of human disease-related mutations in proteins. Hum Mutat 30: 1237-1244, 2009.

28. Capriotti E and Altman RB: Improving the prediction of disease-related variants using protein three-dimensional structure. BMC Bioinformatics 12 (Suppl 4): S3, 2011.

29. Capriotti E, Calabrese R, Fariselli P, Martelli PL, Altman RB and Casadio R: WS-SNPs\&GO: a web server for predicting the deleterious effect of human protein variants using functional annotation. BMC Genomics 14 (Suppl 3): S6, 2013.

30. Cartegni L, Wang J, Zhu Z, Zhang MQ and Krainer AR: ESEfinder: a web resource to identify exonic splicing enhancers. Nucleic Acids Res 31: 3568-3571, 2003.

31. Punta M, Coggill PC, Eberhardt RY, Mistry J, Tate J, Boursnell C, Pang N, Forslund K, Ceric G, Clements J, et al: The Pfam protein families database. Nucleic Acids Res 40 (Database issue): D290-D301, 2012.

32. Larkin MA, Blackshields G, Brown NP, Chenna R, McGettigan PA, McWilliam H, Valentin F, Wallace IM, Wilm A, Lopez R, et al: Clustal W and Clustal X version 2.0. Bioinformatics 23: 2947-2948, 2007

33. Waterhouse AM, Procter JB, Martin DM, Clamp M and Barton GJ: Jalview Version 2 - a multiple sequence alignment editor and analysis workbench. Bioinformatics 25: 1189-1191, 2009.

34. Yeo G, Burge CB, Hoon S and Venkatesh B: Variation in sequence and organization of splicing regulatory elements in vertebrate genes. Proc Natl Acad Sci USA 101: 15700-15705, 2004.

35. Fairbrother WG, Yeh RF, Sharp PA and Burge CB: Predictive identification of exonic splicing enhancers in human genes. Science 297: 1007-1013, 2002.

36. Zhang XH, Kangsamaksin T, Chao MS, Banerjee JK and Chasin LA: Exon inclusion is dependent on predictable exonic splicing enhancers. Mol Cell Biol 25: 7323-7332, 2005.

37. Adzhubei IA, Schmidt S, Peshkin L, Ramensky VE, Gerasimova A, Bork P, Kondrashov AS and Sunyaev SR: A method and server for predicting damaging missense mutations. Nat Methods 7: 248-249, 2010.

38. Friedl W and Aretz S: Familial adenomatous polyposis: experience from a study of 1164 unrelated german polyposis patients. Hered Cancer Clin Pract 3: 95-114, 2005

39. Liang J, Lin C, Hu F, Wang F, Zhu L, Yao X, Wang Y and Zhao Y: APC polymorphisms and the risk of colorectal neoplasia: a HuGE review and meta-analysis. Am J Epidemiol 177: $1169-1179,2013$ 
40. Guerreiro CS, Cravo ML, Brito M, Vidal PM, Fidalgo PO and Leitão CN: The V1822D APC polymorphism interacts with fat, calcium and fiber intakes in modulating the risk of colorectal cancer in Portuguese persons. Am J Clin Nutr 85: 1592-1597, 2007.

41. Menéndez M, González S, Blanco I, Guinó E, Peris M, Peinado MA, Capellá G and Moreno V: Colorectal cancer risk and the APC V1822D variant. Int J Cancer 112: 161-163, 2004

42. Nakagawa H, Murata Y, Koyama K, Fujiyama A, Miyoshi Y, Monden M, Akiyama T and Nakamura Y: Identification of a brain-specific APC homologue, APCL and its interaction with beta-catenin. Cancer Res 58: 5176-5181, 1998.

43. Wachsmannova-Matelova L, Stevurkova V, Adamcikova Z, Holec V and Zajac V: Polymorphisms in the adenomatous polyposis coli gene in Slovak families suspected of FAP. Neuro Endocrinol Lett 30 (Suppl 1): S25-S28, 2009.

44. Herrmann SM, Adler YD, Schmidt-Petersen K, Nicaud V, Morrison C, Paul M and Zouboulis ChC: The concomitant occurrence of multiple epidermal cysts, osteomas and thyroid gland nodules is not diagnostic for Gardner syndrome in the absence of intestinal polyposis: a clinical and genetic report. Br J Dermatol 149: 877-883, 2003.

45. Shu Z, Yanqin H and Ying Y: Hereditary colorectal cancer in china. Hered Cancer Clin Pract 3: 155-164, 2005.

46. Cartegni L, Chew SL and Krainer AR: Listening to silence and understanding nonsense: exonic mutations that affect splicing. Nat Rev Genet 3: 285-298, 2002.

47. Pagani F and Baralle FE: Genomic variants in exons and introns: Identifying the splicing spoilers. Nat Rev Genet 5: 389-396, 2004.
48. Grosso AR, Martins S and Carmo-Fonseca M: The emerging role of splicing factors in cancer. EMBO Rep 9: 1087-1093, 2008.

49. Bechtel JM, Rajesh P, Ilikchyan I, Deng Y, Mishra PK, Wang Q Wu X, Afonin KA, Grose WE and Wang Y, et al: The Alternative Splicing Mutation Database: a hub for investigations of alternative splicing using mutational evidence. BMC Res Notes 1: 3 , 2008.

50. Covaciu C, Grosso F, Pisaneschi E, Zambruno G, Gregersen PA, Sommerlund M, Hertz JM and Castiglia D: A founder synonymous COL7A1 mutation in three Danish families with dominant dystrophic epidermolysis bullosa pruriginosa identifies exonic regulatory sequences required for exon 87 splicing. Br J Dermatol 165: 678-682, 2011.

51. Tournier I, Vezain M, Martins A, Charbonnier F, Baert-Desurmont S, Olschwang S, Wang Q, Buisine MP, Soret J, Tazi J, et al: A large fraction of unclassified variants of the mismatch repair genes MLH1 and MSH2 is associated with splicing defects. Hum Mutat 29: 1412-1424, 2008.

52. Pagani F, Raponi M and Baralle FE: Synonymous mutations in CFTR exon 12 affect splicing and are not neutral in evolution. Proc Natl Acad Sci USA 102: 6368-6372, 2005.

53. Krawczak M, Reiss J and Cooper DN: The mutational spectrum of single base-pair substitutions in mRNA splice junctions of human genes: causes and consequences. Hum Genet 90: 41-54, 1992.

54. Nouri N, Fazel-Najafabadi E, Behnam M, Nouri N, Aryani O, Ghasemi M, Nasiri J and Sedghi M: Use of in silico tools for classification of novel missense mutations identified in dystrophin gene in developing countries. Gene 535:250-254, 2014. 